\title{
Sensibilidad a los antibióticos en bacterias Gram negativas de bulbos de cebolla en Tierra Blanca de Cartago
}

\author{
Andrea Quesada ${ }^{1}$, Juan Salvador Chin², Paula Aguilar ${ }^{3}$, Karla Ruiz ${ }^{4}$ \\ 1. Centro de Investigación en Enfermedades Tropicales; andrea.quesada@ucr.ac.cr \\ 2,3. Laboratorio de Metabolismo y Degradación de Contaminantes, CICA, 4Laboratorio de Ecotoxicología, CICA.
}

Recibido: 03 julio 2017

Aceptado: 13 octubre 2017

\begin{abstract}
RESUMEN
El objetivo de este estudio fue identificar géneros bacterianos en bulbos de cebolla sanos y bulbos que presentaban síntomas, de la zona de Tierra Blanca de Cartago y determinar la susceptibilidad a los antibióticos gentamicina y tetraciclina, dos de los antibióticos más usados en la agricultura en Costa Rica. El cultivo de la cebolla se practica en diferentes regiones del país, principalmente en la zona de Cartago. Este cultivo puede ser atacado por una gran variedad de plagas y enfermedades que pueden disminuir el crecimiento y la producción, causar daños y desfigurar los bulbos impidiendo su comercialización. Las bacterias que atacan los cultivos causan grandes pérdidas económicas, por eso se han buscado diversos métodos para controlarlas, entre ellos, el uso de antibióticos como tetraciclina y gentamicina. La selección y diseminación en la naturaleza de cepas resistentes a los antibióticos es una práctica que se debe controlar, con el fin de mantener un balance ecológico que favorezca el predominio de bacterias susceptibles y asegurar el tratamiento efectivo de las enfermedades infecciosas humanas.
\end{abstract}

Palabras clave: perfil de sensibilidad a antibióticos, gentamicina, tetraciclina, cebolla, bacteria.

\begin{abstract}
Sensitivity to antibiotics of Gram negative bacteria in onion bulbs in tierra blanca, cartago

The aim of this study was to determine the prevalence of different bacterial genera in healthy onion bulbs and bulbs aqueous presenting symptoms of Llano Grande area of Carthage and determine susceptibility to gentamicin and tetracycline antibiotics, two of the most widely used antibiotics agriculture in Costa Rica. The onion cultivation is practiced in different regions of the country, mainly in the area of Tierra Blanca, Cartago. This culture is not in a sterile environment, and hence can be attacked by a variety of pests and diseases that can reduce the growth, reduce
\end{abstract}

production, disfiguring damage and preventing its marketing bulbs. Pests which attack crops bacteria cause great economic losses, so various methods have been sought to control, including antibiotics, such as, tetracycline and gentamicin. The selection and dissemination in the nature of strains resistant to antibiotics is a practice that should be controlled in order to maintain an ecological balance that favors the predominance of susceptible bacteria and ensure effective treatment of human infectious diseases. The objective of this study was to determine the prevalence of different bacterial genera in healthy onion bulbs and bulbs aqueous presenting symptoms of Tierra Blanca area of Cartago and determine susceptibility to the antibiotic gentamicin, and tetracycline.

Key words: antibiotic sensitivity profile, gentamicin, tetracycline, onion crop, bacteria.

\section{Introducción}

La cebolla (Allium cepa L.) se considera originaria de Pakistán y regiones cercanas en Asia Central (Valivov, 1951). Puede crecer bajo un amplio rango de climas, desde templado hasta tropical. De acuerdo con la FAO, el área mundial cultivada con cebolla en el año 2012 fue cercana a los 4,2 millones de hectáreas (ha), con una producción total de aproximadamente $82,8 \mathrm{mi}$ llones de toneladas. China es el mayor productor a nivel mundial con una producción de 20,5 millones de toneladas (FAOSTAT, 2015).

En Costa Rica el área cultivada con cebolla en el año 2013 fue cercana a 1400 ha y la producción fue de aproximadamente 41700 toneladas (SEPSA, 2015). La producción nacional de esta hortaliza se ubica en tres zonas principales, 
que son la zona alta, que comprende la zona norte de Cartago, incluyendo las comunidades de Tierra Blanca, Cot y Llano Grande, donde se concentra la mayor parte de la producción nacional, aproximadamente el $87 \%$, y donde también se produce papa y zanahoria; el Valle Central, que incluye las provincias de San José, Alajuela y Heredia, y la zona de Bagaces en la provincia de Guanacaste. (SEPSA, 2015; Granados, 2013). Las condiciones geográficas y climáticas de la zona norte de Cartago (1600-2500 msnm, $16^{\circ} \mathrm{C}-22^{\circ} \mathrm{C}$ ) permiten que se realice dos ciclos del cultivo al año (Granados, 2013).

En Costa Rica, la cebolla se encuentra entre las diez hortalizas más consumidas en la dieta (PIMA, 2012) y es considerado un alimento de uso popular generalizado y su importancia nutricional es similar a la mayoría de hortalizas (Granados, 2013). Es fuente de vitaminas y minerales, así como, de antioxidantes, con propiedades antibacterianas, antimicóticas y anticarcinogénicas (Grunda, 2005). Su consumo puede ser como alimento fresco, por ejemplo, en ensaladas, o procesado como condimento, cebolla deshidratada o como parte de vegetales mixtos, encurtidos, entre otros (MAG, 2007).

El cultivo de la cebolla al realizarse en ambientes abiertos está expuesto a diversas plagas y enfermedades que pueden disminuir su crecimiento, rendimiento, causando daño o deformaciones en los bulbos, lo que impide su comercialización. Por ejemplo, los ácaros e insectos pueden transmitir infecciones virales, $\mathrm{y}$ predisponer al ataque de hongos y bacterias (Brewster, 2008).

Las bacterias que atacan los cultivos causan pérdidas económicas, por eso se han buscado diversos métodos para controlarlas. Los programas actuales de manejo de enfermedades de plantas se enfocan en la prevención, la cual se basa en cuatro principios básicos: (1) la exclusión del patógeno de la finca o plantación; (2) la erradicación del agente causal de enfermedad, antes de que se distribuya y establezca en un área; (3) la resistencia, que se basa en el desarrollo de plantas resistentes a las infecciones de hongos, bacterias o nemátodos, y (4) la protección, que incluye el uso de barreras químicas, como la aplicación de antifúngicos, antibióticos y nematicidas (Maloy, 2005).

Bacterias de los géneros Erwinia, Xanthomonas, Clavibacter y Pseudomonas se han reportado comúnmente como fitopatógenos en cultivos de hortalizas (Vidaver, 2002, Granados, 2013). A pesar de la importancia de las bacterias fitopatógenas en el cultivo de la cebolla en Costa Rica, la información sobre este tema es muy escasa y poco disponible. A la fecha hay únicamente diez productos comerciales registrados para uso agrícola como antibiótico o bactericida en el país que contienen como ingredientes activos, ya sea individualmente o en mezclas, gentamicina, oxitetraciclina, estreptomicina, kasugamicina, 2-(tiocianometiltio) benzotiazol (TCMTB), sulfato de cobre y citrato de plata. Solamente un producto que contiene una mezcla de estreptomicina y oxitetraciclina está permitido para ser utilizado en el cultivo de cebolla, mientras que para el cultivo de papa, están registrados productos que contienen estreptomicina, oxitetraciclina, gentamicina, TCMTB y sulfato de cobre (SFE, 2015).

Existen cuestionamientos acerca de las aplicaciones constantes en dosis recomendadas por el fabricante de gentamicina en las actividades agrícolas la cuales podrían generar resistencia en bacterias potencialmente patógenas para seres humanos (Vidaver, 2002), sin embargo, no se ha demostrado que esto ocurra y se ha concluido que es poco probable que suceda, tanto para este como para otros antibióticos (Stockwell y Duffy, 2012).

El objetivo de este estudio fue determinar diferentes géneros bacterianos que afectan bulbos de cebolla de la zona de Tierra Blanca, Cartago mediante la aplicación de análisis bioquímico y pruebas de susceptibilidad a dos distintos antibióticos gentamicina y tetraciclina.

\section{Materiales y métodos}

Las muestras de cebolla se recolectaron en la zona de Tierra Blanca de Cartago entre los meses de octubre y noviembre del año 2014 al final del periodo de cosecha y se almacenaron en refrigeración $\left(8^{\circ} \mathrm{C}\right)$ durante 24 horas. Los análisis 

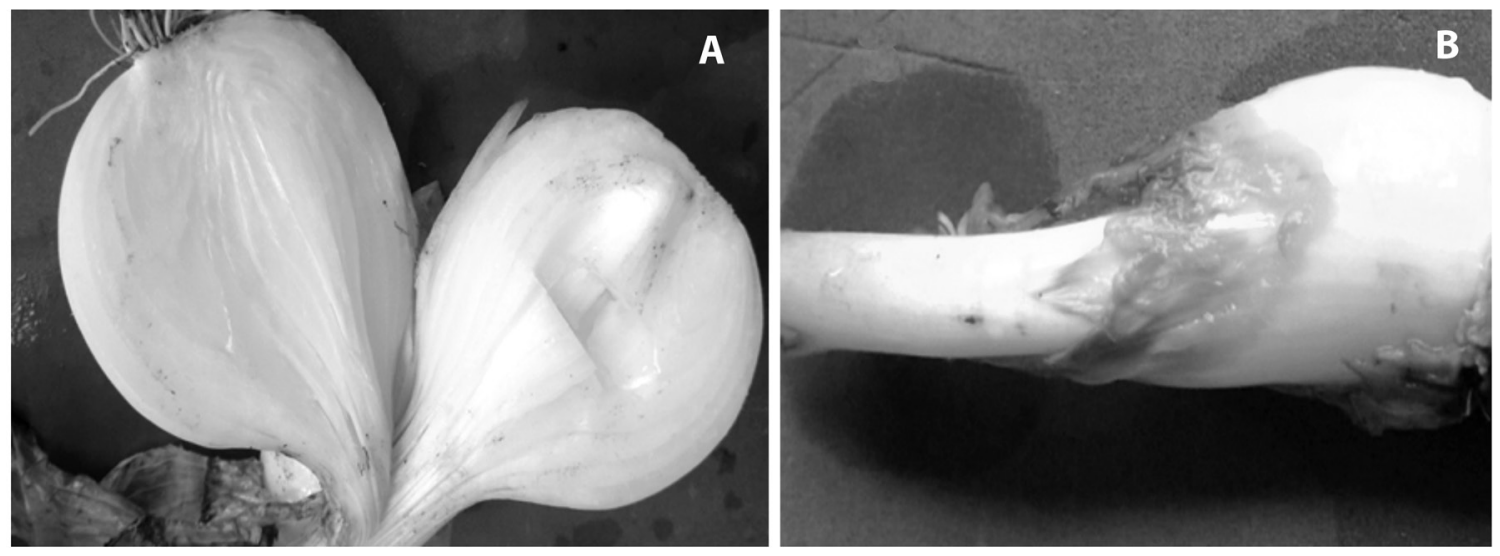

Figura 1. Bulbo de cebolla asintomático. 1b Bulbo de cebolla sintomático. Ambos de Tierra Blanca, Cartago.

se realizaron en el Laboratorio de Fitopatología del Centro de Investigación en Protección de Cultivos de la Universidad de Costa Rica.

Se analizaron y procesaron treinta bulbos, dieciocho sanos y doce que presentaban síntomas de pudrición bacteriana, aquellos con podredumbre de tipo bacteriano que se humedece por completo el tejido y despide olor (Wang, A. 2013) Figura 1.

Aislamiento de bacterias: se procesó por separado diez gramos de tejido interno y $10 \mathrm{~g}$ de tejido sano de cada uno de los bulbos, cada uno en $90 \mathrm{~mL}$ de agua peptonada estéril al $1 \%$.

Se realizaron diluciones seriadas (en agua peptonada estéril al 1\%) de cada una de las muestras hasta $10^{-5} \mathrm{y}$ se depositaron $100 \mu \mathrm{L}$ de cada dilución por duplicado en platos con agar MacConkey, el cual es un medio selectivo y diferencial que permite recuperar bacterias Gram negativas (Rodríguez, Coronado, García. 2005), y se incubaron a $30{ }^{\circ} \mathrm{C}$ durante $48 \mathrm{~h}$.

Posteriormente, se seleccionaron colonias bacterianas a partir de los platos Petri con la concentración adecuada para observación individual de cada una de estas y se rayaron en agar tripticasa soya (ATS) y se incubaron nuevamente a $30^{\circ} \mathrm{C}$ durante $24 \mathrm{~h}$.

A cada una de las cepas se les realizó tinción de Gram, medio triple sugar iron (TSI), el cual permite diferenciar bacterias fermentadoras y no fermentadoras de azúcares (Rodríguez, Coronado, García. 2005), y la prueba de oxidasa. Además, cada una de ellas se identificó usando un sistema comercial de pruebas bioquímicas BIOLOG III según las indicaciones del fabricante.

Pruebas con antibióticos: la susceptibilidad a los antibióticos de las cepas aisladas se determinó por difusión en agar usando mono-discos impregnados con antibióticos comerciales según la técnica Kirby Bauer (Prescott, Harley, Klein. 2004). El diámetro de los halos de inhibición fue medido e interpretado según las recomendaciones del National Comittee for Clinical Laboratory Standard (NCCLS, 1997). En todos los casos se realizaron ensayos con los antibióticos tetraciclina (TE $30 \mu \mathrm{g})$ y gentamicina $(\mathrm{CN}$ $10 \mu \mathrm{g}$ ) por triplicado para cada cepa, así como, cepas control.

\section{Resultados y discusión}

Se recuperó un total de veintiocho aislamientos bacterianos, algunos géneros bacterianos se recuperaron más de una vez. Los resultados de la caracterización bioquímica de las bacterias Gram negativas aisladas se presentan en las figuras 2 y 3 , estos resultados revelaron principalmente la presencia de enterobacterias en bulbos asintomáticos, así como, en aquellos que no presentaban síntomas.

La identificación bioquímica permitió determinar la presencia de los mismos géneros bacterianos en bulbos de cebolla, tanto sanos, como sintomáticos, lo anterior indica que son parte de la microflora ambiental en los campos 


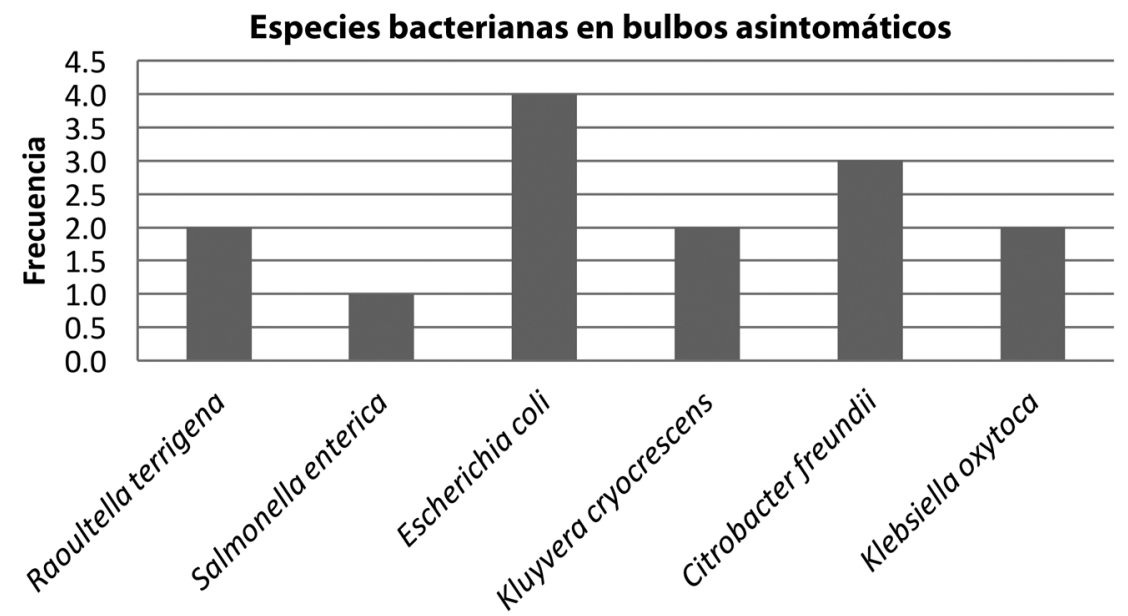

Figura 2. Aislamientos bacterianos recuperadas de bulbos de cebolla asintomáticos (A. cepa) recolectadas en la zona de Tierra Blanca Cartago, Costa Rica. 2014.

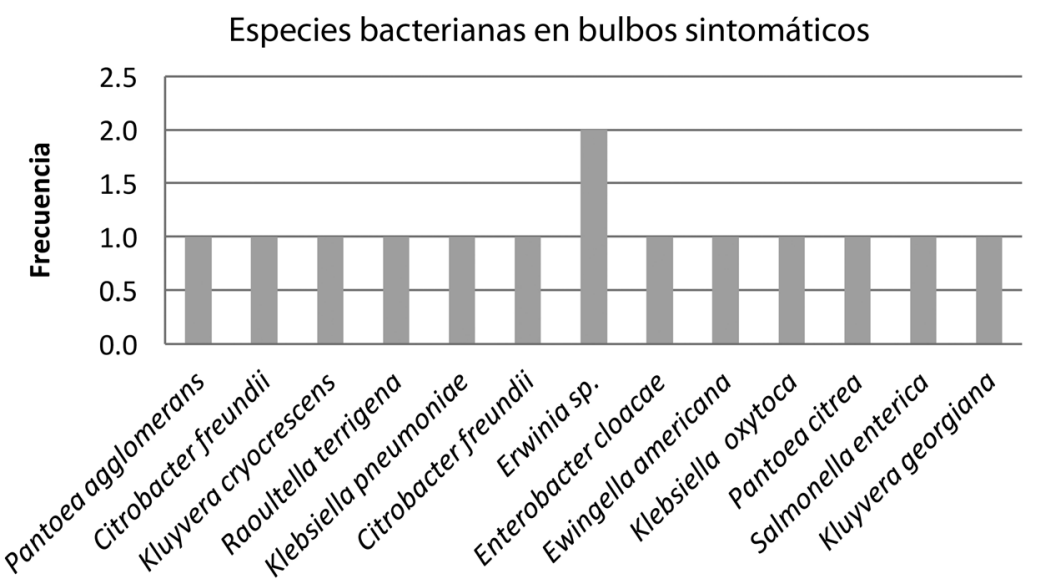

Figura 3. Cepas bacterianas recuperadas de bulbos de cebolla sintomáticos ( $A$. cepa) recolectadas en la zona de Tierra Blanca Cartago, Costa Rica. 2014.

de siembra. En ambos tipos de bulbos se encontraron: Raoultella terrigena, Salmonella enterica, Kluyvera cryocrescens, Citrobacter freundii y Klebsiella oxytoca. La presencia de géneros considerados fitopatógenos, Pantoea, Erwinia y Enterobacter se encontraron solamente en cultivos sintomáticos: (Granados, 2013).

$R$. terrigena es una enterobacteria, previamente se encontraba en el género Klebsiella, es un bacilo Gram negativo, reportado en hábitats acuáticos y terrestres (Murray, Holmes, Auken. 2005), el primer aislamiento de esta especie bacteriana fue reportada en 1981 (Izard et al. 1981).

Cepas de Citrobacter han sido reportadas previamente en vegetales (Uzeh, Alade, Bankole.
2009). Este género está compuesto por bacilos Gram negativos aerobios que se encuentran frecuentemente en el agua, suelo, comida y el tracto intestinal de animales y humanos. Se sabe que estos microorganismos pueden producir infecciones importantes en seres humanos y otros animales, especialmente en hospederos inmunocomprometidos (Flaherty, García-Houchins, Chudy, Arnow, 1993). También han sido asociados a meningitis neonatal y absceso cerebral (Joaquín, Khna, Russel, Al Fayez. 1991).

La especie $S$. enterica se recuperó tanto en bulbos sintomáticos como asintomáticos, son bacterias Gram negativas, anaerobios facultativos y morfológicamente se parecen a bacterias 
entéricas. Miembros del género Salmonella producen infecciones en humanos y en algunos animales (Mahon, Lehman, Manuselis. 2007). Muchos casos de salmonelosis se han atribuido al consumo de pollo por formar parte de la microbiota de esta ave (Tauxe, Kruse, Hedberg. 1997). Sin embargo, ha venido en aumento el número de casos por esta bacteria asociados a productos frescos, tanto frutos como vegetales, debido a la habilidad de Salmonella a adherirse e invadir tejido vegetal (Hanning, Nutt, Ricke. 2009).

Los síntomas por Salmonella aparecen en general de 6 a 48 horas después del consumo de agua o alimentos contaminados. El cuadro clínico de la salmonelosis no tífica (gastroenteritis o enterocolitis) puede incluir diarrea, cefalalgia, dolor abdominal, náusea, vómito, fiebre y deshidratación. Afecta a todos los grupos de edad, con mayor incidencia en niños menores de cinco años y mayores de 60 años de edad, que son los grupos más vulnerables (Pegues, Ohl, Miller. 2002).

Ewingella americana es la única especie de este género y las especies $K$. cryocrescens y $K$. georgiana que pertenecen al género Kluyvera, todas forman parte de las enterobacterias (Mahon et al., 2007), se encontraron en ambos tipos de muestras.

Escherichia coli es un organismo ubicuo, se encuentra dentro del grupo de los coliformes y su presencia en heces humanas es conocida desde 1887. Schardinger y posteriormente Smith (de forma independiente) introdujeron el uso de E. coli y organismos relacionados como indicadores de presencia de patógenos entéricos en agua en 1891 en Australia y 1895 en Estados Unidos respectivamente.

El suelo, el agua de riego, el compost y otros tipos de abono orgánico son fuentes de diferentes organismos, entre ellos, coliformes totales y fecales. En la década de los setenta, numerosos estudios determinaron que las enterobacterias en general no pueden relacionarse directamente con contaminación fecal (Miskimin et al., 1976; Silliker y Gabis, 1976). La aplicación más útil de los coliformes, enterobacterias y E.coli es actualmente indicadores de la calidad y las condiciones higiénicas que presentan los alimentos procesados (Pouch e Ito, 2001).

En bulbos sintomáticos se identificó Pantoea citrea y Pantoea agglomerans, la primera especie se encuentra reportada como agente causal de enfermedades en el cultivo de piña (Goszczynska, 2007), así como, pudrición de bulbos de cebolla (Edens, Gitaitis, Sanders, Nischwitz. 2006), los síntomas que provoca disminuyen la producción y conducen a pérdidas económicas importantes (Walcott, Gitaitis, Castro, Sanders, Díaz-Pérez. 2002). Pantoea agglomerans también puede causar enfermedad y pérdidas económicas sustanciales en cebolla (Schwartz y Mohan, 2008).

La enfermedad conocida como decaimiento del bulbo es provocada por Enterobacter cloacae y fue reportada en Australia desde la década de 1980 (Cother y Dowling, 1986), posteriormente en California (Bishop y Davis, 1990), Colorado (Schwartz and Otto, 2000), Washington (Schroeder, Du Toit L.J., Schwartz. 2009) y más recientemente en Nueva York (Zaid, Bonasera, Beer. 2011). Esta especie puede causar síntomas foliares, sin embargo, sobresalen en bulbos que presentan podredumbre (Schwartz y Mohan, 2008).

Las bacterias que pertenecen al género Erwinia pueden infectar plantas en el campo, las hojas se marchitan y se secan en etapas tardías, al realizar cortes transversales en los bulbos se observa el tejido dañado, viscoso y se percibe su olor característico a putrefacción. Los bulbos afectados se vuelven suaves y aguados. Usualmente la pudrición blanda es causada por E. carotovora subsp. carotovora (sinónimo: Pectobacterium carotovorum subsp. carotovorum) o por E. chrysanthemi (sinónimo: Dickeya chrysanthemi) (Schwartz y Gent, 2007).

La infección bacteriana generalmente requiere heridas causadas por el proceso de pesaje del bulbo, potenciada por el viento, la lluvia, el granizo, insectos o al cortar durante la cosecha. También es favorecida por el salpique del agua, los aerosoles, los equipos y los trabajadores contaminados, así como, los insectos que propagan bacterias. Las bacterias fitopatógenas se encuentran también en el agua de riego y son fácilmente difundidas en la cosecha. Estas bacterias pueden 
sobrevivir entre los cultivos, suelo y restos de cultivos (Schwartz y Gent, 2007).

Los resultados obtenidos de las pruebas de Kirby-Bauer (realizadas por triplicado) se observan en las figuras 4 y 5. La interpretación de los resultados obtenidos en cada antibiótico se realizó con la tabla que relaciona el diámetro de la zona de inhibición con el grado de resistencia microbiana. Una bacteria sin zona de inhibición (crecimiento alrededor del disco con antibiótico), es resistente a las concentraciones normales alcanzadas (Prescott, Harley, Klein. 2004).

Se trabajó con los antibióticos gentamicina y tetraciclina, ya que ambos se utilizan en medicina en el ser humano y veterinario, estos dos antibióticos y la estreptomicina, son los antimicrobianos más ampliamente utilizados en la horticultura (Vidaver, 2002). Estas sustancias generalmente se pulverizan de las partes aéreas de los cultivos o directamente en el suelo de los cultivos a concentraciones que van desde $50 \mathrm{y}$ hasta 300 ppm (Mc Manus, Stockwell, Sundin, Jones, 2002).

En el caso de gentamicina el diámetro reportado que indican resistencia es $<12 \mathrm{~mm}, 13 \mathrm{~mm}$ $14 \mathrm{~mm}$ intermedio y $>15 \mathrm{~mm}$ indica sensibilidad (Sacsaquispe y Velásquez, 2002). Los resultados obtenidos indican que Ewingella americana y Enterobacter cloacae presentan resistencia, mientras que, el resto de las cepas analizadas son sensibles a este antibiótico (figura 4).

Con respecto a los diámetros reportados para tetracilina, $<14 \mathrm{~mm}$ se consideran resistentes, $>19 \mathrm{~mm}$ se considera sensible y diámetros entre $15 \mathrm{~mm}$ y $18 \mathrm{~mm}$ se considera intermedio (Prescott, Harley, Klein. 2004). En este análisis, microorganismos con sensibilidad intermedia en el caso de $R$. terrigena, Citrobacter freundii, E. coli y S. enterica. El diámetro obtenido en las demás bacterias indica que el ochenta y cinco por ciento son sensibles a este antibiótico (figura 5).

Las pruebas realizadas indican que la mayoría de especies encontradas presentan sensibilidad a ambos antibióticos. El productor de cebolla de la zona de Cartago que facilitó el material vegetal para este estudio indicó que en las últimas cosechas no aplicó ningún tipo de fungicidas ni antibióticos, pues ha logrado realizar un manejo integrado de enfermedades usando otras opciones de control, (Angulo, comunicación personal, 2015). Sin embargo, no especificó el número de cosechas de no aplicación, y es conocido el uso de antibióticos, tales como, tetraciclinas y gentamicina, así como, estreptomicina en estos cultivos.

En el caso específico del manejo de enfermedades, su manejo integrado provoca que el productor no dependa únicamente del uso de

\section{Prueba de sensibilidad a gentamicina}

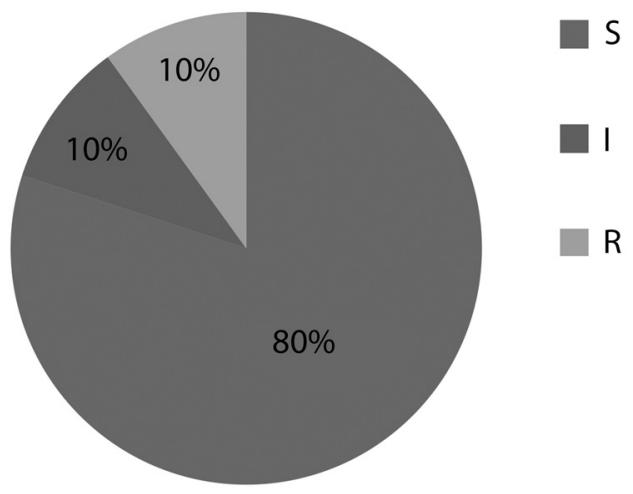

Figura 4. Patrón de sensibilidad / resistencia a la gentamicina por parte de los bacilos Gram negativos aislados en bulbos de cebolla recolectadas en la zona de Tierra Blanca Cartago, Costa Rica, 2014.

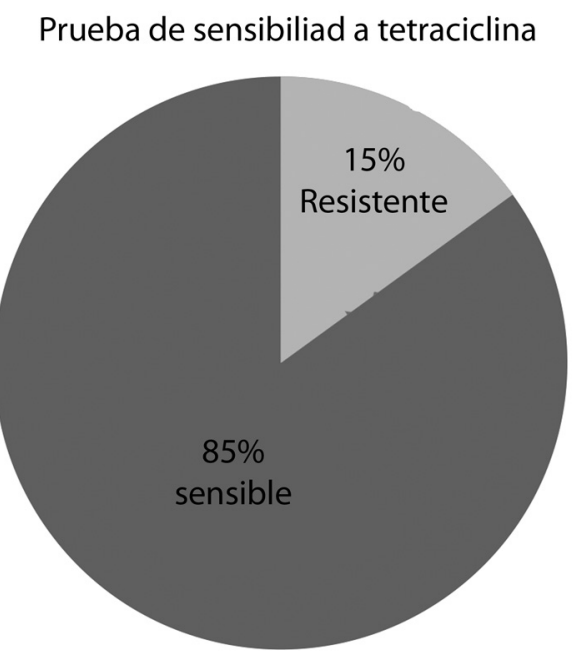

Figura 5. Patrón de sensibilidad / resistencia a la tetraciclina por parte de los bacilos Gram negativos aislados en bulbos de cebolla recolectadas en la zona de Tierra Blanca Cartago, Costa Rica, 2014. 
agroquímicos, pues incluye otras prácticas con el fin de cumplir tanto con las exigencias de la productividad como con la necesidad de la sostenibilidad. El manejo integrado de enfermedades consiste en combinar las diversas opciones para su control en forma eficiente, considerando el equilibrio entre la rentabilidad, la protección del ambiente y la salud del ser humano. El manejo integrado requiere de la consideración del agro-ecosistema en su conjunto a la hora de tomar decisiones sobre la aplicación de tácticas de combate de enfermedades (Arauz, 2011).

Aunque los resultados obtenidos indican que las bacterias encontradas no son francamente resistentes a los antibióticos usados, no deja de ser un tema trascendental, ya que algunas cepas sí presentaron un patrón intermedio en presencia de la tetraciclina y la gentamicina, lo que indica la pérdida de sensibilidad a estos antibióticos y la eventual resistencia debido a las frecuentes aplicaciones. Esta situación es una alerta para los productores y los consumidores de hortalizas, ya que, el incremento en el uso de antibióticos y la respectiva presión selectiva que ejercen, es el factor más importante que contribuye a la aparición de diversas clases de resistencia (Ang, Ezike, Asmar. 2004).

En la actualidad se ha obtenido un avance considerable en la comprensión de la respuesta de las bacterias a los bactericidas. La resistencia puede ser una propiedad natural de un organismo (intrínseca) o conseguida por mutación o adquisición de plásmidos (autorreplicación, ADN extracromosómico) o transposones (cromosomal o integrado en plásmidos, cassettes de ADN transmisibles) (Frost, Leplae, Summers, Toussanint. 2005).

Y la resistencia se puede presentar como resultado de mutaciones cromosomales o por intercambio de material genético mediante el transporte de genes de resistencia a través de varios mecanismos como: transducción, que se define como: transferencia de cualquier parte de un genoma bacteriano, cuando un fago atemperado (genoma del virus que se encuentra inserto en el ADN bacteriano) durante su fase de ensamblaje, encapsula este material. Si el fragmento de ADN que queda envuelto es totalmente bacteriano se denomina transducción generalizada y si sólo se encapsula parte del genoma bacteriano pero se conserva el genoma viral se habla de transducción especializada (Prescott, Harley, Klein. 2004).

Un segundo mecanismo es la conjugación: transferencia de material genético contenido en plásmidos de una bacteria a otra a través de una hebra sexual; estos plásmidos usualmente contienen genes que le confieren resistencia a drogas, antisépticos y desinfectantes (Levy, 2004). Otro mecanismo es la transformación: transferencia de genes desde un ADN desnudo de una bacteria previamente lisada a otra que lo recibe y lo incorpora a su genoma (Levy, 1998). Y el último mecanismo es la transposición: movimiento de una sección de ADN (transposon) que puede contener genes para la resistencia a diferentes antibióticos y otros genes casete unidos en equipo para expresión de un promotor en particular (Prescott, Harley, Klein. 2004, Levy, 2004).

Chatterjee y Starr (1972) observaron que cepas de E. coli fueron capaces de transferir factores de resistencia a tetraciclina (Factor tet R) a nueve especies de Erwinia; en este mismo estudio se demostró que Shigella flexneri pudo transferir un factor de múltiple resistencia a cloranfenicol, estreptomicina y tetraciclina, a cuatro cepas de Erwinia. Actualmente se sabe que los elementos genéticos conocidos como integrones tienen la habilidad de capturar grupos de genes del ambiente (agua, suelo), e incorporarlos mediante recombinación en sitios específicos (Miko, Pries, Schoetes, Helmuth. 2005). Cepas en el ambiente de Salmonella y E. coli pueden estar en contacto con altas concentraciones de antimicrobianos o con especies resistentes a éstos, por lo que es factible la selección en campo de cepas resistentes.

La selección y diseminación en la naturaleza de cepas resistentes a los antibióticos es una práctica que se debe controlar, con el fin de mantener un balance ecológico que favorezca el predominio de bacterias susceptibles y asegurar el tratamiento efectivo de las enfermedades infecciosas humanas. El uso indiscriminado de antibióticos en diversas prácticas, incluyendo las médicas, veterinarias y agrícolas resulta en 
una presión selectiva sobre las bacterias, contribuyendo a la selección de microorganismos con patrones de resistencia a antibióticos (Galland, Hyatt, Crupper, Acheson, 2001). La presencia y persistencia de bacterias resistentes a antibióticos ha sido descrita en diferentes ambientes, incluyendo suelos (Gallardo, Ruiz, Marco, Towner, Vila. 1999), agua superficial y potable (Sayah, Kaneene, Johnson, Miller. 2005) y alimentos (Saldar y Armstrong, 2003) y representa un creciente problema de Salud Pública.

Algunas instituciones, como la Sociedad Americana de Microbiología y otras, han presionado a la EPA para que no se importen a Estados Unidos frutas y verduras cuyos cultivos fueron tratados con gentamicina, ya que no se cuentan con datos sobre si presentan niveles residuales de este antibiótico (Vidaver, 2002).

Países como Estados Unidos ha realizado estudios de residuos de oxitetraciclina y estreptomicina en frutos y hojas de plantas listas para el consumo, y se han reportado resultados de "no detectables" o "no tóxicos". A pesar del uso considerable de este tipo de sustancias en países de América Latina, aún no se cuenta con información sobre la cantidad que se utiliza ni la presencia de residuos de antibióticos en productos vegetales (Vidaver, 2002). En Costa Rica sería importante implementar un programa de monitoreo de este tipo de sustancias, especialmente tomando en cuenta que no todos los agricultores guardan el periodo de carencia en el uso de agroquímicos antes de ofrecer el producto en el mercado nacional (Galt, 2009).

\section{Bibliografía}

Ang, J.Y., Ezike, E., Asmar, B.I. (2004). Antibacterial resistance. Indian J Pediat. 71: 229-239.

Arauz F. (2011). Fitopatología, un enfoque agroecológico. Segunda edición. Editorial de la Universidad de Costa Rica. San José, Costa Rica. 434-437p.

Bishop A.L., Davis R.M. (1990). Internal decay of onions caused by Enterobacter cloacae. Plant Dis. 74:692-694.
Brewster J.L. (2008). Onions and other vegetable alliums. Crop production sciences in horticulture. $2^{\text {nd }}$ edition. N.15 CAB International, USA. 171.

Chatterjee A.K., Starr M.P. (1972). Transfer among Erwinia spp. and other enterobacteria of antibiotic resistance carried on R Factors. J. Bacteriol. 112:576-584.

Cother E.J., Dowling V. (1986). Bacteria associated with internal breakdown of onion bulbs and their possible role in disease expression. Plant Pathol. 35:329-336.

Edens D.G., Gitaitis R.D., Sanders F.H., Nischwitz C. (2006). First report of Pantoea agglomerans causing a leaf blight and bulb rot of onions in Georgia. Plant Dis 90:1551.

FAO. 2015. http://faostat.fao.org/site/567/DesktopDefault. aspx?PageID=567\#ancor, consultado el 28 de agosto de 2015

Flaherty J.P., García-Houchins S., Chudy R., Arnow P.M. (1993). An outbrake of Gram-negative bacteremia traced to contaminated O-Rings in reprocessed dialyzers. Ann. Intern. Med. 119:1072-1078.

Frost L.S., Leplae R., Summers A.O., Toussanint A. (2005) Mobile genetic elements: The agents of open source evolution. Nat Rev Microbiol. 3: 722-732.

Galt R.E. (2009). It just goes to kill Ticos: national market regulation and the political ecology of farmers' pesticide use in Costa Rica. J. Pol. Ecol.16:1-33.

Galland J., Hyatt D., Crupper S., Acheson D. (2001). Prevalence, antibiotic susceptibility and diversity of Escherichia coli $\mathrm{O} 157: \mathrm{H} 7$ isolates from a longitudinal study of beefcattle feedlots. Appl Environ Microbiol. 67:1619-1627.

Gallardo F., Ruiz J., Marco F., Towner K.J., Vila J. (1999) Increase in incidence of resistance to ampicillin, chloramphenicol and trimethoprim in clinical isolates of Samonella serotype typhimurium with investigation of molecular epidemiology and mechanisms of resistance. J Med Microbiol 48:367-74.

Goszczynska T. (2007). Emerging diseases of maize and onion caused by bacteria belonging to the Genus Pantoea. The Faculty of Natural and Agricultural Sciences University of Pretoria. Pretoria, SAF. 5-12p.

Granados M. (2013). Problemas fitosanitarios de la cebolla en Costa Rica. Primera edición. Facultad de Ciencias 
Agroalimentarias. Universidad de Costa Rica, San José, Costa Rica. 1-8.

Grunda N. (2005). Impact of environmental factors on product quality of greenhouse vegetables for fresh consumption. Crit. Rev. Plant Sci. 24:227-247

Hanning I., Nutt J.D., Ricke S. (2009). Salmonellosis Outbreaks in the United States Due to Fresh Produce: Sources and Potential Intervention Measures. Foodborne pathogens and disease. 6: 635-648.

Izard D., Ferragut C., Gavini F., Kersters K., De Ley J., Leclerc H. (1981). Klebsiella terrigena, a new species from soil and water. Int J Syst Bacteriol. 31:116-127.

Joaquín A., Khna S., Russel N., Al Fayez N. (1991). Neonatal meningitis and bilateral cerebellar abscesses due to Citrobacter freundii. Pediatr. Neurosurg. 17:23-24.

Levy S.B. (1998). The challenge by antibiotic resistance. Sci Am. 278:46-53.

Levy S.B. (2004). Antibacterial resistance worldwide: Causes, challenges and responses. Nature Med. 10 (Suppl): 122-129.

MAG (Ministerio de Agricultura y Ganadería). (2007). Caracterización de la agro-cadena regional de cebolla. San José, CRC. 1-31.

Mahon C., Lehman D., Manuselis G. (2007). Textbook of diagnostic microbiology. Elsevier. St Louis, MO. USA. 433-440.

Maloy O.C. 2005. Plant disease management. The Plant Health Instructor: file:///E:/TFG\%20Gentamicina/ Plant\%20Disease\%20Management.htm. DOI: 10.1094/PHI-I-2005-0202-01.

Mc Manus P.S., Stockwell V.O., Sundin G.W., Jones A.L. (2002). Antibiotic use in plant agriculture. Annu. Rev. Phytopathol. 40:443-465.

Miko A., Pries K., Schoetes A., Helmuth R. (2005). Molecular mechanisms of resistance in multidrug-resistant ser. of Salmonella enterica isolated from foods in Germany. J. Antimicrobial Chem. 56:1025-1033.

Miskimin D.K., Berkowits K., Solberg M., Riha W.E., Frankie W.C., Buchanan R.L., O’leary V. (1976). Relationships between indicator organisms and specific pathogens in potenctially hazardous foods. J. Food. Sci. 41:1001.
Murray P., Holmes B., Auken H. (2005). Citrobacter, Klebsiella, Enterobacter, Serratia, and other Enterobacteriaceae. In: P. Borriello et al., editors, Tropley and Wilson's Microbiology and Microbial Infections. Volume 2. 10th ed. London: Hodder Arnold. p.1474-1507.

NCCLS. (National Committee of Clinical Laboratory Standard). (1997). Performance standard for antimicrobial disk susceptibility test, 6th ed. Approved Standard Documents M2. National Committee of Clinical Laboratory Standard, Wayne. PA, USA. 24-30p.

Pegues D.A., Ohl M.E., Miller S.I. (2002). Salmonella, including Salmonella typhi. In: Blaser MJ, Smith PD, Ravdin JI, Greenberg HB, Guerran RL (eds.). Infections of the gastrointestinal tract. 2nd ed. Philadelphia: Lippincott Williams \& Wilkins. 669-697p.

PIMA (Programa Integral de Mercado Agropecuario). 2013. Tendencias del consumo de frutas, hortalizas y pescado en las familias de Costa Rica. Costa Rica. 35-45p.

Prescott L., Harley J., Klein D. (2004). Microbiología. Quinta edición. McGraw Hill Interamericana. Madrid, España. 145-162p.

Pouch F., Ito K. (2001). Compendium of methods for the microbiological examination of foods. Fourth edition. American Public Health Association. WA, USA. 83-100p.

RODRÍGUEZ E., Coronado M., H F., GARCÍA J. (2005). Bacteriología general: Principios y prácticas de laboratorio. Editorial Universidad de Costa Rica. Costa Rica. 134, 213, 217, 265p.

Sacsaquispe R., Velásquez J. (2002). Manual de procedimientos para la prueba de sensibilidad antimicrobiana por el método de difusión. Serie de normas técnicas N. 30. Instituto nacional de salud. Lima, PER.

Saldar A., Armstrong D. (2003). Antimicrobial activities against 84 Listeria monocytogenes isolates from patients with sistemic listeriosis at a comprensive cancer center (1955-1997). J Clinical Microbiol. 49:483-485.

Sayah R., Kaneene J., Johnson Y., Miller R. (2005). Patterns of antimicrobial resistance observed in Escherichia coli isolates obtained from domestic and wild animal 
fecal samples, human sewage and surface water. Appl Environ Microbiol. 71:1394-1404.

Schroeder B.K., Du Toit L.J., Schwartz H.F. (2009). First report of Enterobacter cloacae causing onion bulb rot in the Columbia Basin of Washington State. Plant Dis. 93: 323.

Schwartz H.F., Gent D. (2007). Onion soft rot. High Plains IPM Guide, a cooperative effort of the University of Wyoming, University of Nebraska, Colorado State University and Montana State University, USA.

Schwartz H.F., Mohan S.K. (2008). Compendium of onion and garlic diseases and pests, $2^{\text {nd }}$ ed. American Phytopathological Society (APS Press), St. Paul, MN, USA.

Schwartz H.F., Otto K. (2000). First report of a leaf and bulb decay of onion by Pantoea ananatis in Colorado. Plant Dis. 84:808.

SEPSA. Secretaría Ejecutiva de Planificación Sectorial Agropecuaria (SEPSA). 2014. Boletín Estadístico Agropecuario N ${ }^{\circ}$ 25. Costa Rica. 17-40.

SFE. Servicio Fitosanitario del Estado (SFE). 2015. https:// www.sfe.go.cr/insumosys/Principal.html. Consultado el 29 de agosto de 2015.

Silliker J.H., Gabis D.A. (1976). ICMSF methods studies. VII indicator tests as substitutes for direct testing of dried foods and feeds for Salmonella. Can. J. Microbiol. 22:971.
Stockwell V.O., Duffy B. (2012). Use of antibiotics in plant agriculture. Rev. sci. tech.Off. int. Epiz., 31: 199-210

Tauxe R., Kruse H., Hedberg C. (1997). Microbial hazards and emerging issues associated with produce, a preliminary reportto the national advisory committee on microbiologic criteriafor foods. J Food Prot. 60:1400-1408.

Uzeh R.E., Alade F.A., Bankole M. (2009). The microbial quality of pre-packed mixed vegetable salad in some retail outlets in Lagos Nigeria. Africal Journal of Food Science. 3: 270-272.

Vavilov N.I. (1951). The origin, variation, immunity and breeding of cultivated plants. Chronicles of botany 3: 1 .

Vidaver A.K. (2002). Uses of antimicrobials in plant agriculture. Clin. Infect. Dis. 34:107-110.

Walcott R.R., Gitaitis R.D., Castro A.C., Sanders F.H., Díaz-Pérez J.C. (2002). Natural infestation of onion seed by Pantoea ananatis, causal agent of center rot. Plant Dis 86:106-111.

Wang A. (2013). Enfermedades bacterianas de la cebolla. In: M. Granaddos (ed). Problemas fitosanitarios de la cebolla en Costa Rica. Primera edición. Facultad de Ciencias Agroalimentarias,Universidad de Costa Rica, San José, Costa Rica.

Zaid A.M.A., Bonasera J.M., Beer S.V. (2011). First report of Enterobacter decay caused by Enterobacter cloacae in New York. Plant Dis. 95:1581. 